\title{
Recessive hypophosphataemic rickets, and possible aetiology of the 'vitamin D-resistant' syndrome
}

\author{
T. C. B. STAMP and L. R. I. BAKER \\ From the Metabolic Ward, Royal National Orthopaedic Hospital, Stanmore, and the Department \\ of Nephrology, St. Bartholomew's Hospital, London
}

\begin{abstract}
Stamp, T. C. B., and Baker, L. R. I. (1976). Archives of Disease in Childhood, 51, 360. Recessive hypophosphataemic rickets, and possible aetiology of the 'vitamin D-resistant' syndrome. Two out of 3 children of a first-cousin marriage presented with severe rickets in infancy and are now adult. Their disease has shown continued activity, marked resistance to treatment with vitamin $\mathrm{D}$, early fusion of cranial sutures, greatly increased bone density, nerve deafness, and life-long hypophosphataemia unaffected by treatment. Both parents and a third sib were normal clinically and biochemically. Blood grouping supported both stated paternity and parental consanguinity. Genetics of this unique disease can only be explained satisfactorily on the basis of autosomal recessive transmission, a mode not previously reported in primary hypophosphataemia.

This homozygous disease resembles an exaggerated form of common X-linked rickets, though it is caused by a different gene. Although rare, it is particularly important because of the information it provides on the pathogenesis of both forms. We propose that both syndromes may result from multiple target organ unresponsiveness to 1,25-dihydroxycholecalciferol in intestine, kidney, bone, and parathyroid gland.
\end{abstract}

Heritable primary hypophosphataemia due to an isolated renal tubular leak of phosphate is the most common type of metabolic ('vitamin D-resistant') rickets and is nearly always transmitted by an Xlinked dominant gene (Winters et al. 1958; Williams and Winters, 1972; Burnett et al. 1964). Sporadic cases due to new mutation are not uncommon (Burnett et al., 1964) and such patients may be expected to transmit the disease to their offspring in the X-linked manner. Autosomal dominant transmission has been suggested in very rare instances (Harrison, Lifshitz, and Johnson, 1966) but no other inheritance has been reported. The characteristic radiological, clinical, and biochemical features of X-linked rickets have been precisely delineated (Williams and Winters, 1972; Dent, Round, and Stamp, 1973); its apparently independent abnormalities in bone, kidney, and intestine present a pathogenetic problem which has been unanswered for nearly 40 years (Albright, Butler, and Bloomberg, 1937).

We report for the first time a form of severe primary hypophosphataemic rickets in 2 sibs in which

Received 11 August 1975. autosomal recessive transmission is the only satisfactory explanation of inheritance. This phenotype is similar to the $\mathrm{X}$-linked form despite the involvement of a different gene, and this similarity helps provide a hypothesis for the natural history of both syndromes.

\section{Patients.}

\section{Case reports}

Male IV.1. Born November 1953. Bow legs at 6 months worsened when he began to walk at 11 months. At 18 months he had thickening of the cranial sutures with early fusion, frontal bossing, and all physical signs of rickets except for myopathy. $X$-rays at this time (May 1955) are shown in Fig. 1A. Serum calcium was $11 \mathrm{mg} / 100 \mathrm{ml}$, phosphorus was abnormally low for his age at $3 \cdot 2 \mathrm{mg} / 100 \mathrm{ml}$, and alkaline phosphatase was raised at 42 King-Armstrong units. From the age of 4 months he had received up to 4000 IU vitamin $D$ daily; dosage was increased to 250000 IU daily but reduced to 50000 IU daily after an episode of hypercalcaemia. Despite radiological improvement, his bow legs remained. At the age of 5 (Fig. 2) he was apparently backward for his age, with bilateral perceptive deafness and optic atrophy. Bilateral osteotomies were performed, bone histology showing increased osteoid width and the bone 


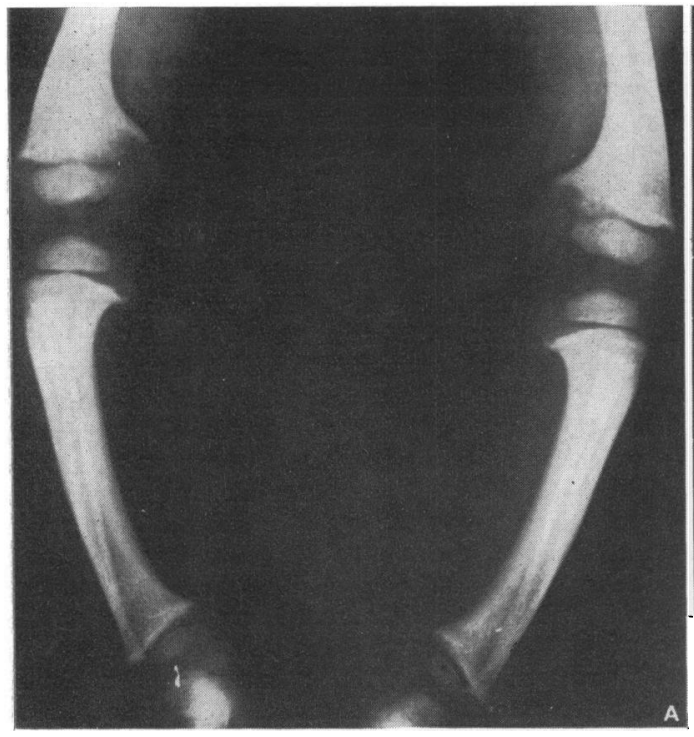

Fig. 1.-X-rays of 2 affected sibs.

(A) IV.1 aged 19 months; lower limbs showing rickets.

(B) IV.1 aged 20 years, pelvis and hips showing gross osteosclerosis, widening, and poor remodelling.

(C) IV.3 aged 17 years, skull showing increased density and 'copper-beating'.

$\mathrm{X}$-rays are nearly identical in each patient.
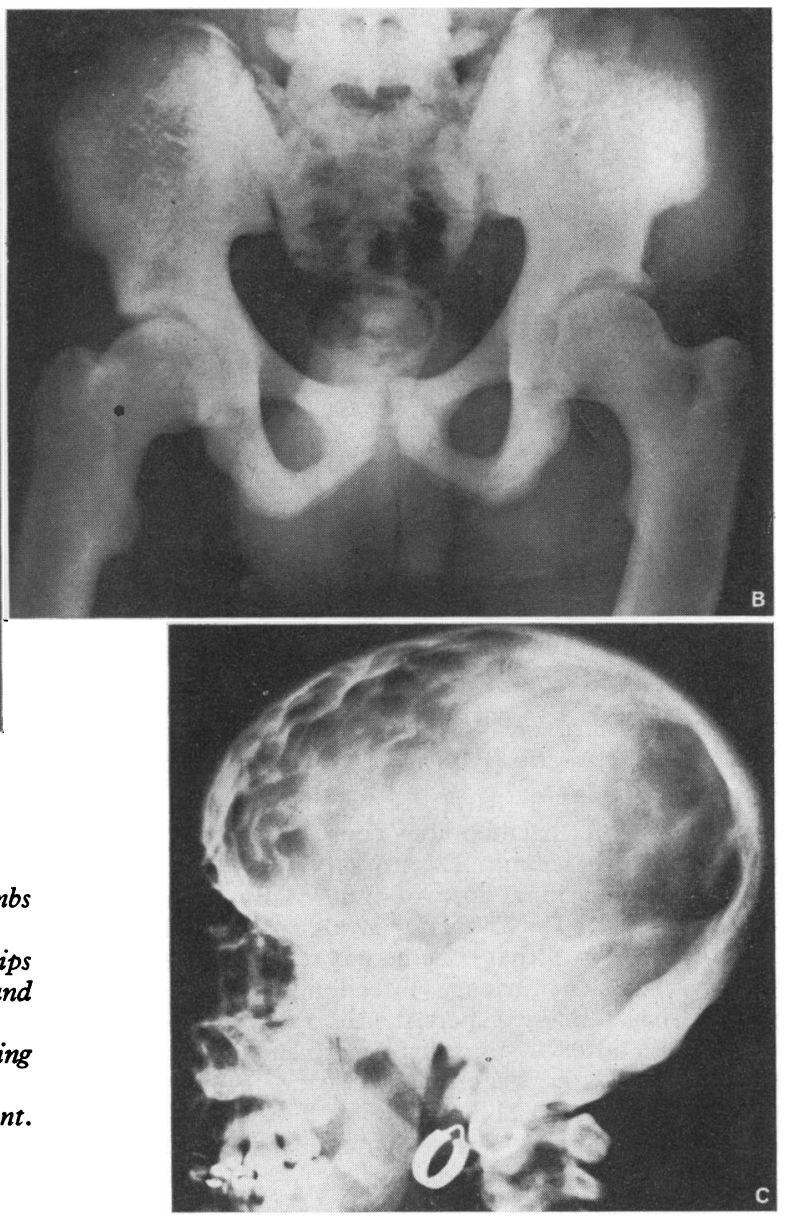

normal, serum parathyroid hormone normal $(<0 \cdot 15 \mathrm{ng} /$ ml) (kindly performed by Dr. J. L. H. O'Riordan). Urine showed a trace of albumin; no aminoaciduria. 24-hour urine calcium excretion $188 \mathrm{mg}$; total hydroxyproline excretion normal $(42-61 \mathrm{mg} / 24 \mathrm{~h})$; creatinine clearance $120 \mathrm{ml} / \mathrm{min}$; maximum urine concentration and dilution normal. Renal tubular phosphate reabsorption was low (see Table). $X$-rays showed generalized and marked increase in bone density (Fig. 1B), the long bones had extremely thick cortices, and the skull had a characteristic copper-beaten appearance. The optic foramina were normal but tomography of the internal auditory canal showed marked narrowing at several points throughout its length. Two small stones were present in the right kidney. Iliac crest biopsy showed a marked excess of osteoid tissue on the trabeculae and around the cortical lacunae; there was no excessive resorption. Microradiographs showed patchy perilacunar demineralization. Radio-iron and radio-chromium studies (kindly performed by Professor J. Stewart) showed 


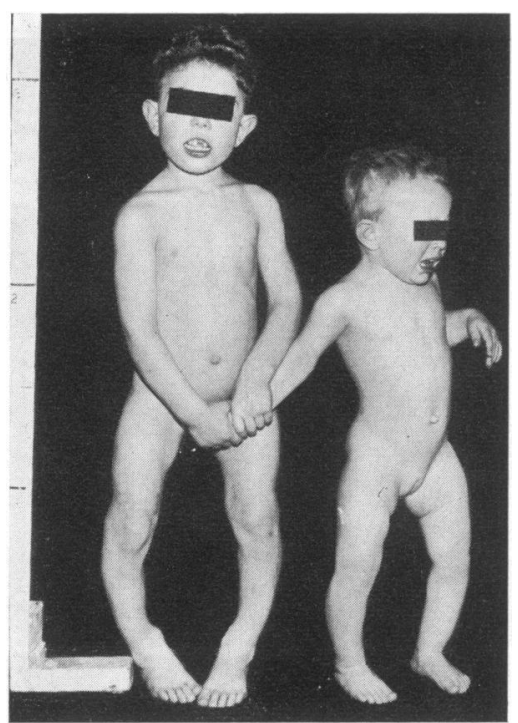

Fig. 2.-Affected sibs. IV. 1 and 3 aged 5 years and 2 years, respectively, showing rachitic deformities.

neither splenic haemopoiesis nor haemolysis. After treatment with vitamin $D_{2}$, initially in a dose of $5 \mathrm{mg}$ daily and then in a dose of $2 \mathrm{mg}$ daily, plasma 25hydroxyvitamin D (25-OHD) levels rose to plateau at $300 \mathrm{ng} / \mathrm{ml}$. Since that time he has remained well apart from a transient urinary infection. Alkaline phosphatase has remained persistently raised (17-19 KA units), and after a phosphate supplement of $900 \mathrm{mg}$ phosphorus daily begun in January 1975, alkaline phosphatase rose to $21 \mathrm{KA}$ units in February and to 25 KA units in April. Severe hypophosphataemia (1.6$1.7 \mathrm{mg} / 100 \mathrm{ml}$ ) has persisted.
Female IV.3. The younger sister, born December 1956. Bow legs were noticed when she first stood unaided at 18 months. At 26 months she had premature closure of skull sutures, a bony protuberance at the anterior end of the sagittal sinus, bowing of the tibiae and femora, and other signs of rickets (Fig. 2). Investigations: serum calcium $10.6 \mathrm{mg} / 100 \mathrm{ml}$; phosphorus abnormally low for her age at $2.9 \mathrm{mg} / 100 \mathrm{ml}$; alkaline phosphatase raised at $41 \mathrm{KA}$ units. Urea and electrolytes were entirely normal, and urinary phosphate/ creatinine clearance ratio was 0.05 (normal range 0.05$0 \cdot 15$ ). Treatment with small doses of calciferol was followed by bilateral osteotomies. Histology confirmed rickets. She was then treated with vitamin D initially 200000 IU daily, but after an episode of intoxication (plasma calcium $16.6 \mathrm{mg} / 100 \mathrm{ml}$ ) dosage was reduced to 50000-100000 IU daily. Bilateral perceptive deafness was noted at the age of 5 and she required a hearing aid. At the age of 12 intelligence testing (Wechsler scale) showed an IQ of 94. Menarche occurred at her 15th birthday. Bone histology at the time of further osteotomies in 1972 showed excess osteoid and periosteal new bone formation in a fibula. Hypophosphataemia with normal urinary phosphorus excretion persisted. She grew satisfactorily along the 3rd centile.

She was admitted to hospital in May 1974, with no symptoms except for severe deafness and shyness. Height $152 \mathrm{~cm}$; skeletal proportions: crown to pubis 80 $\mathrm{cm}$, pubis to sole $74 \mathrm{~cm}$, span $157 \mathrm{~cm}$. $X$-rays showed great increase in bone density, similar to her brother, and her skull had a copper-beaten appearance (Fig. 1C). Investigations (taking vitamin $\mathrm{D}_{2} 100000$ IU daily): plasma calcium $10 \cdot 0-10.3 \mathrm{mg} / 100 \mathrm{ml}$; phosphorus $2 \cdot 1-2.5 \mathrm{mg} / 100 \mathrm{ml}$; alkaline phosphatase raised at $16 \mathrm{KA}$ units; plasma $25-\mathrm{OHD} 260 \mathrm{ng} / \mathrm{ml}$; serum parathyroid hormone normal $(<0 \cdot 15 \mathrm{ng} / \mathrm{ml})$ (kindly measured by Dr. J. L. H. O'Riordan); urea and electrolytes normal. Renal tubular phosphate reabsorption was low (see

TABLE

Plasma and urinary biochemistry in a family with autosomal recessive hypophosphataemic rickets in 2 of its members

\begin{tabular}{|c|c|c|c|c|c|c|}
\hline \multirow{2}{*}{ Subject } & \multirow{2}{*}{$\begin{array}{c}\text { Age } \\
\text { (years) }\end{array}$} & \multicolumn{3}{|c|}{ Plasma chemistry } & \multirow[b]{2}{*}{ Cp } & \multirow[b]{2}{*}{$\%$ TRP } \\
\hline & & $\begin{array}{c}\mathrm{Ca} \\
(\mathrm{mg} / 100 \mathrm{ml})\end{array}$ & $\underset{(\mathrm{mg} / 100 \mathrm{ml})}{\mathbf{P}}$ & $\begin{array}{c}\text { Alkaline } \\
\text { phosphatase } \\
\text { (KA units) }\end{array}$ & & \\
\hline $\begin{array}{l}\text { Father (III.5) } \\
\text { Mother (III.6) }\end{array}$ & $\begin{array}{l}49 \\
53\end{array}$ & $\begin{array}{r}10 \cdot 2 \\
9 \cdot 9 \\
9 \cdot 9 \\
10 \cdot 0\end{array}$ & $\begin{array}{l}3 \cdot 8 \\
3 \cdot 5 \\
2 \cdot 8^{\star} \\
4 \cdot 2 \\
3 \cdot 8\end{array}$ & $\begin{array}{l}7 \\
8 \\
7 \\
7\end{array}$ & 16 & 83 \\
\hline $\begin{array}{l}\text { Son (IV.2) } \\
\text { Affected son (IV.1) } \\
\text { Affected daughter (IV.3)t }\end{array}$ & $\begin{array}{l}18 \\
20 \\
17\end{array}$ & $\begin{array}{c}10 \cdot 4 \\
10 \cdot 1-10 \cdot 3 \\
10 \cdot 0-10 \cdot 3\end{array}$ & $\begin{array}{l}3 \cdot 2^{\star} \\
4 \cdot 0^{\star} \\
1 \cdot 9-2 \cdot 1 \\
2 \cdot 1\end{array}$ & $\begin{array}{c}14 \\
16-19 \\
15-16\end{array}$ & $\begin{array}{l}12 \\
17 \\
31 \ddagger \\
31\end{array}$ & $\begin{array}{l}92 \\
86 \\
74 \ddagger \\
64\end{array}$ \\
\hline
\end{tabular}

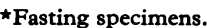

†Receiving vitamin D 100000 I.U. daily.

$\ddagger 3$ days after beginning vitamin $D_{2} 5 \mathrm{mg}$ daily.

$\mathrm{Cp}$, phosphate clearance; \%TRP, \% tubular reabsorption of phosphate. 
Table). She was discharged with her treatment unchanged on vitamin $D_{2} 100000$ IU daily. Bone histology showed excess osteoid tissue and a halo of deceased mineralization around the osteocyte lacunae. Tetracycline labelling of the calcification front was present.

Family. The parents, who came from southern Italy, were first cousins and the family pedigree is shown in Fig. 3.

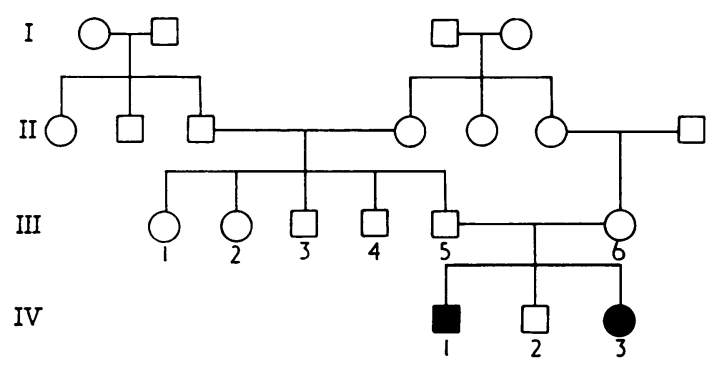

Fig. 3.-Family tree showing first cousin marriage and disease in 2 sibs out of 3.

Father III.5. Born July 1925, and healthy. He had been told he had rickets as a child but if so this was clearly very mild; he did not receive treatment with vitamin $D$ but wore splints on his legs at night until the age of 6 . A photograph at the age of 8 showed straight legs. On examination he was well proportioned and had mild myopia. Plasma chemistry and tests of urinary phosphate excretion were normal (see Table). Bone $x$-rays were normal; the long bones were slim, straight, and without evidence of earlier growth arrest.

Mother III.6. Born July 1921, was healthy with no previous significant illness, and was short (height 154 cm) but normally proportioned. Bone $x$-rays were entirely normal; plasma biochemistry and indices of urinary phosphate excretion normal (see Table).

Male sib IV.2. The third sib was born in 1955. Normal, healthy, no relevant past history. Height 173 $\mathrm{cm}$; lower limbs normal on $x$-rays. Plasma biochemistry and indices of urinary phosphate excretion normal (see Table). Full blood grouping was kindly performed by Dr. R. Sanger, and statistical calculation showed increased likelihood of stated (over random) paternity of 6 times, 15 times, and 11 times, respectively, in the case of IV.1, IV.2, IV.3. Blood group genes in the parents were between 2 and 4 times less likely to be found in random pairs of (English) spouses.

\section{Discussion}

The presence of severe primary hypophosphataemic rickets in two out of three sibs, offspring of healthy consanguineous parents with a third normal sib, can be satisfactorily explained only on the basis of autosomal recessive inheritance. There is no previous published report of this situation. Significance of the father's possible childhood rickets is uncertain but in view of his present normality it is either irrelevant or it represents a mild heterozygous state; clearly X-linkage could not be involved.

Our patients' homozygous disease shows in an exaggerated form the same abnormalities which occur in the X-linkage syndrome. These involve kidney, intestine, and bone, and in many respects they appear to be unrelated. Thus the kidney in our patients shows an unexplained tubular phosphate leak similar to that occurring in X-linked rickets, and persisting despite adequate control of rickets with high doses of vitamin $D$ even to the point of intoxication. Intestinal calcium absorption is defective in X-linked rickets (not measured in our patients) and this is unaccountable since hypophosphataemia normally enhances it (Nature, 1973). In bone there is in addition to 'vitamin D-resistant' rickets an unaccountable increase in density, the long bones having thick cortices and showing periosteal new bone formation (Williams and Winters, 1972; Dent et al., 1973; Stanbury and Lumb, 1962). Craniostenosis may occur (Williams and Winters, 1972) and gross bony overgrowth in our patients has even caused perceptive deafness. Optic atrophy in sib IV.1 is a little more difficult to explain on this basis since the optic foramina appear normal, and the cause of his splenomegaly remains obscure.

In X-linked hypophosphataemia, rickets (or osteomalacia) ceases when growth stops and alkaline phosphatase levels, previously raised despite adequate therapy, fall to normal adult values (Dent et al. 1973). Clinical osteomalacia sometimes returns in later life. Our patients' exaggerated condition shows continuing disease activity both histologically and biochemically despite their having reached adult stature. Probably only careful long-term treatment has prevented severe deformity. We cannot predict whether they will need life-long treatment with vitamin $\mathrm{D}$, but it seems likely.

In other respects our patients further resemble those with X-linked rickets and contrast with recessive conditions such as vitamin $\mathrm{D}$-dependent rickets and Fanconi syndromes; plasma and urine calcium are normal and they have never shown myopathy; there is no acidosis, glycosuria, aminoaciduria, hypokalaemia, nor diminished urine concentration or excessive renal water loss. Their plasma 25-hydroxyvitamin D levels were consistent with vitamin D dosage as is found in X-linked rickets (Haddad et al. 1973), and serum immuno- 
reactive parathyroid hormone was within normal limits of a routine assay.

Two different genetic defects have thus produced a similar phenotype with the same 'unrelated' abnormalities, and a possible reason may be considered. Increased bone density in these patients is not simply a result of long-term high dosage with vitamin $\mathrm{D}$, since it occurred in $\mathrm{X}$-linked disease in the past before adequate vitamin $\mathrm{D}$ treatment, and it is not found among other hereditary forms of rickets for which equally large doses of vitamin D are given. Our patients with severe osteosclerosis received no higher doses of vitamin $\mathrm{D}$ than are normally required in X-linked rickets. There is strong evidence of mild secondary hyperparathyroidism in patients with primary hypophosphataemia. This is not an adequate explanation for their hypophosphataemia as was originally believed (Albright et al. 1937), the renal tubular phosphate leak being now more correctly regarded as a 'primary' abnormality, and its possible importance may have been overlooked. Histological studies may show parathyroid hyperplasia (Albright and Sulkowich, 1938), and others have recently reported mildly raised circulating parathyroid hormone levels (Arnaud, Glorieux, and Scriver, 1971; Lewy et al. 1972; Reitz and Weinstein, 1973), overt secondary hyperparathyroidism when excessive phosphate supplements are given, and the development of parathyroid adenomata (Thomas and Fry, 1970; Hendrikx, Decraene, and de Moor, 1960). Moreover, the effect of sustained parathyroid hormone infusions in young animals is to produce osteosclerosis (Walker, 1971; Kalu et al. 1970) and parathyroid activity also stimulates periosteal new bone formation, both of which are features in Xlinked rickets and in our patients. Finally, osteosclerosis is common in renal osteodystrophy in which secondary hyperparathyroidism is almost universal. We therefore propose that additional bony abnormalities (not the hypophosphataemia) in X-linked rickets and in our patients result from minor parathyroid overactivity throughout their growth period.

The question then arises as to a possible common cause for mild hyperparathyroidism, renal phosphate leak, and defective intestinal calcium transport. The actions of 1,25-dihydroxycholecalciferol $(1,25$ $\left.(\mathrm{OH})_{2} \mathrm{D}\right)$ on its respective target organs may be relevant. Production of $1,25(\mathrm{OH})_{2} \mathrm{D}$ in X-linked rickets does not appear to be disturbed, since treatment with this active metabolite produces an inadequate response (Glorieux et al. 1973; Brickman et al. 1973). The established target organs of $1,25(\mathrm{OH})_{2} \mathrm{D}$ are intestine, where it enhances calcium absorption (Kodicek, 1974), and bone where it stimulates resorption and may be important for remodelling, especially during growth (Raisz et al. 1972). There is in addition strong evidence for a direct effect of vitamin $\mathrm{D}$ or its metabolites on kidney and on parathyroid glands. In kidney, 25-hydroxycholecalciferol and $1,25(\mathrm{OH})_{2} \mathrm{D}$ stimulate renal tubular phosphate reabsorption (Puschett, Moranz, and Kurnick, 1972a; Puschett et al. 1972b; Pechet and Hesse, 1974) though the mechanism is unknown. However, a vitamin D-dependent calcium-binding protein $(\mathrm{CaBP})$ has recently been shown in kidney (Wassermann, Taylor, and Fullmer, 1974) and since calcium itself also enhances phosphate reabsorption (Pechet and Hesse, 1974) vitamin D may perhaps exert its phosphate effect through renal $\mathrm{CaBP}$. Whatever the actual mechanism it is clear that defective $1,25(\mathrm{OH})_{2} \mathrm{D}$ activity in kidney could result in a renal phosphate leak. A calcium-binding protein has also been shown in parathyroid gland (Oldham, Fischer, and Arnaud, 1972) and there is strong evidence for a direct suppressive effect of vitamin D on parathyroid hormone secretion in humans with nutritional osteomalacia (Rasmussen et al. 1974). If this $\mathrm{CaBP}$ regulates parathyroid hormone secretion by transmitting calcium ions to receptor site(s), then a defect in its response to vitamin D should interfere with normal parathyroid suppression by calcium ions. It seems clear that any defect in a suppressive action of vitamin $\mathrm{D}$ could give rise to mild secondary hyperparathyroidism.

Thus the clinical picture of primary hypophosphataemia may result from multiple target organ unresponsiveness to $1,25(\mathrm{OH})_{2} \mathrm{D}$, the disease(s) being analogous to pseudohypoparathyroidism where there is target organ unresponsiveness to parathyroid hormone. Failure of vitamin D reponsiveness in kidney would produce the lifelong hyperphosphaturia with variable hypophosphataemic rickets in childhood and osteomalacia in adult life; equivalent failure in intestine would produce the paradoxically high faecal calcium excretion, characteristic of rickets; in bone, defective remodelling also leading to dwarfism and craniostenosis would occur; finally, in the parathyroid gland failure of suppression would result in persistent mild parathyroid hyperplasia, completing the picture with osteosclerosis, increased periosteal new bone formation, increased parathyroid sensitivity to phosphate administration, and a tendency to tertiary hyperparathyroidism. A complicated sequence of events follows transport of $1,25(\mathrm{OH})_{2} \mathrm{D}$ to its target organs, from its initial combination with a cytoplasmic receptor protein 


\section{Aetiology of the 'vitamin D resistant' syndrome in hypophosphataemic rickets}

through regulation of DNA transcription to eventual formation of calcium-binding protein(s) (Nature, 1973). A number of genetic abnormalities could theoretically disturb this sequence at different sites and thus produce a similar phenotype. We propose that the natural history of both X-linked and autosomal recessive hypophosphataemic rickets results from separate disturbances of this sequence.

We are grateful to many doctors and nursing staffs who helped in the care of our patients, in particular to Dr. G. S. Udall for referring these patients, Dr. P. J. N. Cox, Dr. W. R. Cattell, Mr. A. Catterall, and Dr. Paul Byers.

Charts of the growth and biochemistry of these patients, and full family blood grouping may be obtained from the authors.

\section{REFERENCES}

Albright, F., Butler, A. M., and Bloomberg, E. (1937). Rickets resistant to vitamin D therapy. American fournal of Diseases of Children, 54, 529.

Albright, F., and Sulkowich, H. W. (1938). The effect of vitamin $\mathrm{D}$ on calcium and phosphorus metabolism. Studies on four patients. Fournal of Clinical Investigation, 17, 305.

Arnaud, C. D., Glorieux, F. H., and Scriver, C. R. (1971). Serum parathyroid hormone in X-linked hypophosphatemia. Science, 173, 845.

Brickman, A. S., Coburn, J. W., Kurokawa, K., Bethune, J. E., Harrison, H. E., and Norman, A. W. (1973). Actions of 1,25 dihydroxycholecalciferol in patients with hypophosphatemia vitamin-D-resistant rickets. New England fournal of Medicine, $289,495$.

Burnett, C. H., Dent, C. E., Harper, C., and Warland, B. J. (1964) Vitamin D-resistant rickets. Analysis of twenty-four pedigrees with hereditary and sporadic cases. American fournal of Medicine, 36, 222.

Dent, C. E., Round, J. M., and Stamp, T. C. B. (1973). Treatment of sex-linked hypophosphataemic rickets (SLHR). Clinical Aspects of Metabolic Bone Disease, p. 427. Ed. by B. Frame, A. M. Parfitt, and H. Duncan. International Congress Series No. 270. Excerpta Medica, Amsterdam.

Glorieux, F. H., Scriver, C. R., Holick, M. F., and DeLuca, H. F. (1973). X-linked hypophosphataemic rickets: inadequate therapeutic response to 1,25-dihydroxycholecalciferol. Lancet, 2, 287.

Haddad, J. G., Chyu, K. J., Hahn, T. J., and Stamp, T. C. B. (1973). Serum concentrations of 25 -hydroxy-vitamin D in sex-linked hypophosphataemic vitamin D-resistant rickets. Fournal of Laboratory and Clinical Medicine, 81, 22.

Harrison, H. E., Lifshitz, F., and Johnson, A. D. (1966). Growth disturbance in hereditary hypophosphatemia. American fournal of Diseases of Children, 112, 290.

Hendrikx, A., Decraene, P., and de Moor, P. (1960). Un cas d'hyperparathyroide associé a une ostéomalacie prononcée. Annales d'Endocrinologie, 21, 293.
Kalu, D. N., Pennock, J., Doyle, F. H., and Foster, G. V. (1970). Parathyroid hormone and experimental osteosclerosis. Lancet, $1,1363$.

Kodicek, E. (1974). The story of vitamin D from vitamin to hormone. Lancet, 1, 325.

Lewy, J. E., Cabana, E. C., Repetto, H. A., Canterbury, J. M., and Reiss, E. (1972). Serum parathyroid hormone in hypophosphatemic vitamin D-resistant rickets. Fournal of Pediatrics, 81, 294.

Nature, (1973). (Editorial.) Regulation of vitamin D metabolism, 245, 180.

Oldham, S. B., Fischer, J. A., and Arnaud, C. D. (1972). Isolation and properties of a calcium-binding protein (CaBP) from normal porcine parathyroid gland (pPTGs) Fourth International Congress of Endocrinology, p. 95. International Congress Series No. 256. Excerpta Medica, Amsterdam.

Pechet, M. M., and Hesse, R. H. (1974). Metabolic and clinical effects of pure crystalline $1 \alpha$-hydroxyvitamin $D_{3}$ and $1 \alpha, 25$ dihydroxyvitamin $\mathrm{D}_{3}$. American fournal of Medicine, 57, 13.

Puschett, J. B., Moranz, J., and Kurnick, W. S. (1972a). Evidence for a direct action of cholecalciferol and 25-hydroxycholecalciferol on the renal transport of phosphate, sodium and calcium. Fournal of Clinical Investigation, 51, 373.

Puschett, J. B., Fernandez, P. C., Boyle, I. T., Gray, R. W., Omdahl, J. L., and DeLuca, H. F. (1972b). The acute renal tubular effects of 1, 25-dihydroxycholecalciferol. Proceedings of the Society for Experimental Biology and Medicine, 41, 379.

Raisz, L. G., Trummel, C. L., Holick, M. F., and DeLuca, H. F. (1972). 1, 25-dihydroxycholcalciferol: a potent stimulator of bone resorption in tissue culture. Science, 175, 768 .

Rasmussen, H., Bordier, P., Kurokawa, K., Nagata, N., and Ogata, E. (1974). Hormonal control of skeletal and mineral homeostasis. American fournal of Medicine, 56, 751.

Reitz, R. E., and Weinstein, R. L. (1973). Parathyroid hormone secretion in familial vitamin D-resistant rickets. New England Fournal of Medicine, 289, 941.

Stanbury, S. W., and Lumb, G. A. (1962). Hypophosphataemic vitamine D-refractory rickets and osteomalacia. Quarterly Fournal of Medicine, 31, 522.

Thomas, W. C., and Fry, R. M. (1970). Parathyroid adenomas in chronic rickets. American fournal of Medicine, 49, 404.

Walker, D. G. (1971). The induction of osteopetrotic changes in hypophysectomized, thyroparathyroidectomized and intact rats of various ages. Endocrinology, 89, 1389.

Wassermann, R. H., Taylor, A. N., and Fullmer, C. S. (1974) Vitamin D-induced Calcium-Binding Protein and the Intestinal Absorption of Calcium. Biochemical Society Special Publication No. 3, p. 55. Ed. by D. R. Fraser.

Williams, T. F., and Winters, R. W. (1972). Familial (hereditary) vitamin D-resistant rickets with hypophosphataemia. The Metabolic Basis of Inherited Disease, p. 1465. Ed. by J. B Stanbury, J. B. Wyngaarden, and D. S. Fredrickson. McGrawHill, New York.

Winters, R. W., Graham, J. B., Williams, T. F., McFalls, V. W. and Burnett, C. H. (1958). A genetic study of familial hypophosphatemia and vitamin D-resistant rickets with a review of the literature. Medicine, 37, 97.

Correspondence to Dr. T. C. B. Stamp, Royal National Orthopaedic Hospital, 234 Great Portland Street, London W1N 6AD. 